\title{
Phenomenology Approach Applicability in Information Systems and Technology Field
}

\author{
Mary Walowe Mwadulo, Collins Otieno Odoyo* \\ Department of Information Technology, School of Computing and Informatics, Masinde Muliro University of Science and Technology, \\ Kakamega, Kenya
}

Received December 23, 2019; Revised March 20, 2020; Accepted March 28, 2020

Copyright $\bigcirc 2020$ by authors, all rights reserved. Authors agree that this article remains permanently open access under the terms of the Creative Commons Attribution License 4.0 International License

\begin{abstract}
Phenomenology is a research approach that is uniquely positioned to help scholars learn from the experience of others. Even though it is a powerful research approach, the nature of phenomenology is qualitatively requiring a more subjective, interpretive stance which makes it incompatible with ICT research which is based on logical, objective and quantifiable procedures. This incompatibility has made ICT scholars shy away from applying it in their research work. However, phenomenology can still be used to explore challenging problems in the field of ICT, by understanding its nature of studies and working to ensure proper alignment between the specific research question and researchers' underlying philosophy. An important finding from the different studies that have applied phenomenology is that empiricism and phenomenology do not oppose each other, rather while empiricism helps understand what happens in ICT use, phenomenology helps to uncover the root cause behind the empirical observation. Therefore, it is important to know areas in ICT research where phenomenology is most suitable. This article examines the applicability of phenomenology approach in the field of ICT by defining phenomenology, explaining the nature of studies that apply it, highlighting the benefits of applying phenomenology approach in the field of ICT, Discussing suitable areas in the field of ICT where phenomenology approach is applied and Revealing areas where phenomenology approach has been applied in the field of ICT.
\end{abstract}

Keywords Phenomenology, ICT, Interpretive Phenomenology, Descriptive Phenomenology, Experiences, Educational Technology

\section{Introduction}

Even though human beings can learn from the experiences of others, in most cases they are unwilling to do so. Maybe because they assume similar circumstances cannot befall them. Or they assume that they can make better decisions in a similar situation, or they reason experiences are subjective therefore unreliably informative than objective data collected from external reality. Despite the assumptions underlying the decision they take, it is important to learn from the experiences of others. After all, the research aims to study a subject to uncover new information and achieving a new understanding of the subject. The new understanding can better be discovered by understanding the experiences of others so that we can pick up new insights about a particular phenomenon [1]. Researchers in the field of ICT shy away from learning these experiences, instead they focus on the cause-effect of the particular phenomena. But to understand the meaning individual ascribes to, ICT researchers need to be able to carefully explore and learn from the experience of others. For instance, the feeling a displaced refugee has when interacting with their loved one through a video chat [2]. Even though some researchers may argue that providing a theoretical explanation is good enough to explain the use of ICT for personal betterment, it is insufficiently adequate to reveal the experience lived by an individual. Therefore, ICT researchers need to learn from the experiences of others.

Phenomenology is a qualitative research approach that is suitable to fill this gap. However, in the field of ICT, it does not have a strong following, because of the different philosophical stance underpinning phenomenology and ICT. While phenomenology takes a humanistic approach which is rooted in the understanding that human activity is the force that creates what we perceive to be the society[3], ICT research takes a positivistic approach in which the world is seen as composed of objects that humans can study, understand and manipulate which is a view accepted by quantitative researchers [4].

This paper is organized as follows; Section II provides 
an overview of the philosophical background of phenomenology. Section III discusses the nature of studies that apply phenomenology approach, section IV highlights the benefits of applying phenomenology in the field of ICT, section V discusses suitable areas in the field of ICT where phenomenology can be applied, section VI Reveal how and where phenomenology approach has been applied in the field of ICT and section VII concludes by presenting challenges of applying phenomenology approach in the field of ICT and emphasizing on new important aspects of the study.

\section{What Is Phenomenology?}

Phenomenology is a qualitative research approach that aims to describe the essence of a phenomenon by exploring it from the viewpoint of those who have experienced it, to understand the meaning participants ascribe to that phenomenon [3]. Manen in [5] describes it as a study of an individual's lived experience of the world that emphasizes that those who have experienced phenomena can communicate to the outside world. It aims to describe the meaning of these experiences about what and how it was experienced [3]. It seeks to understand a person's experience rather than provide a causal explanation of the experience.

There are other qualitative research approaches such as narrative, grounded theory, ethnography, and case study. They contrast with phenomenology in terms of foundational consideration. The narrative approach relies on stories told by individuals about their lives. They are more interested in the manner in which the individuals make sense of their experiences rather than the experience itself. The grounded theory focuses on common experiences and seeks to explain the activity or event [6]. Ethnography is concerned with studying the sites rather than the individuals. Therefore, ethnographers are more informants than participants [7]. The case study aims to understand the entire case in the totality of the environment It not only dwells on the present action of an individual but also the past, environment, emotions, and thoughts. All these approaches differ with phenomenology in that phenomenology focuses on shared or lived experiences of an individual [3]. The phenomenologist becomes a participant in the experience.

There are different types of phenomenology rooted in different schools of philosophy, therefore the choice of a phenomenological research methodology requires the scholar to reflect on the philosophical stance embraced by that particular phenomenology.

The two most popular phenomenological research methodologies are hermeneutic (interpretive) and transcendental (descriptive) phenomenology. Transcendental phenomenology is grounded in Husserl's work in which he argued that the mind or objective science closely represents reality and offers a better way to understand the world [8]. Transcendental is rooted in the philosophical notion of consciousness and how one comes to known the world. On the other hand, hermeneutic phenomenology challenges many of the practical and philosophical assumptions associated with transcendental phenomenology. This is manifested in the way hermeneutic phenomenologist move away from looking at the consciousness of a phenomenon to looking at how things manifest and matter in the world [8].

\section{Field of Studies That Have Applied Phenomenology}

Phenomenology being a qualitative research approach is most suitable for qualitative research. It is applied in a variety of fields. It is applied in medicine to try to understand the experiences a patient goes through during illness, to illuminate the experience and enable the health care providers to enhance their understanding in providing care for the patient. Carel [9] developed a phenomenological method through a concept taken from Marleau-Ponty and demonstrated the usefulness of phenomenology in illuminating the experience a patient goes through during illness. Neubauer et al [1] employed phenomenology methodology for health professions education scholars. They used transcendental and hermeneutic phenomenology approached to understand the experiences of others and gain new insight on how to maximize the effectiveness of feedback, workplace-based learning, and clinical reasoning. However, they warned that even though phenomenology is a valuable tool and an important research strategy for health professional educators, its application can be challenging when one is not familiar with the philosophical underpinning or methodology application. Even though many studies have reported success rate in using phenomenology in health research, Kuller [10] questions whether phenomenology is the best approach for health research. He argues that the phenomenology approach alone will improve how a patient describes the disease, but may not results in reducing the disease burden in the human population. Therefore he suggests the need to link phenomenological, etiologic and social approaches for successful and high-quality research.

Phenomenology has also been applied in the field of psychology in which researchers have attempted to understand the experience general practitioners go through when dealing with patients with emotional problems or mental disorders. Both phenomenology and psychology are concerned with consciousness in general as well as with specific acts of consciousness like perception, memory, comprehension of meaning, reasoning, etc. Yet, the theoretical orientation and perspective in which consciousness is studied in psychology are highly different from that of phenomenology [11]. Davidsen [12] 
conducted an empirical study aimed at exploring the experiences General Practitioners (GP) go through when handling patients with emotional problems or mental disorders. He applied both descriptive and interpretive phenomenology by interviewing several GPs to gain insight into different perceptions and experiences they undergo when delivering therapy, other psychological interventions and interpersonal interactions during consultations.

Phenomenology approaches have also been applied in the field of anthropology to understand how anthropologists think of lived experiences such as illness, morality, sensory perception, creativity among others. It aids anthropologist to reconfigure what it means to be human, to have a body, to suffer and to heal [13]. Desjarlais and Throop [13] conducted a review to explore the most significant dimensions and findings of phenomenology approaches in anthropology. They pointed out implications inherent in such approach and addressed ways in which they have contributed to analytic perception employed in anthropology. They further pointed out the main critiques of the phenomenology approached applied in the field of anthropology.

Phenomenology methodology has also been applied in the field of religious education to try and understand the experiences a scholar goes through in the religion he seeks to study to understand the meaning and manifestations of the religious phenomena of the particular religion. Leech [14] presented a discussion on the importance of a phenomenological approach for religious education. He pointed out the elements of the method and concluded on the importance of applying the phenomenology approach in religious studies. To evaluate the effectiveness of practicing religious tolerance Awang and Ramli [15] presented a discussion on applying the phenomenology approach in teaching comparative religious education.

Another field of study that has seen the application of phenomenology is the education sector. It has been applied in education communication technology [8], to understand the set of expectations of millennial teachers in teaching technology [16] and to understand students' experiences in using technology for learning [17].

\section{Benefits of Applying Phenomenology Approach in the Field of ICT}

The field of ICT can greatly benefit from applying the phenomenology approach. Phenomenology being a qualitative approach can greatly complement quantitative methods by enriching and validating its findings [18]. In the field of ICT, the use of qualitative research in educational technology is greatly encouraged. Even though phenomenology has not been fully utilized as a research methodology in the field of ICT, some of the benefits that can be realized by its application include: (1) Getting an in-depth insight of experiences in a multifaceted and comprehensive manner. (2) The approach provides a unifying framework for a research agenda on experiences with technology. (3) It provides a theoretical and philosophical framework as well as a consistent methodology and methods. (4) it provides clear guidelines on sample selection, data collection, data analysis, ethics and validity, which would facilitate its adoption in the field; and (5) generally strengthening the qualitative basis of educational technology research [19].

\section{Suitable Areas in the Field of ICT Where Phenomenology Approach Is Applied}

Even though different philosophical stance underpins phenomenology and ICT research, phenomenology approaches can still be applied in some instances in the ICT field. Phenomenology needs not to be applied in all the processes and or procedures encompassing ICT research, rather some specific facets of ICT can be solved using this approach[2]. However, the use of phenomenology in ICT is limited because ICT is treated as a tool to achieve a means to an end rather than a means itself. Others view ICT as a social construct that results from a complicated process, influenced by cultural, economic and political forces[20]. For instance, phenomenology can be applied in data collection, qualitative data analysis, in trying to understand ICT scarcity in various sectors and in understanding the technological attitude of people in contemporary society.

\section{A. Phenomenology in data collection in ICT research}

Applying Phenomenology in data collection in ICT research would imply constructing research questions that reflect the experiences of an individual as an object of inquiry. Example of some research questions that can guide phenomenologist research in ICT include; "What is the ICT use experience for a rural elder to videoconference with a healthcare professional?", "What is it like for a rural farmer to use ICT to manage his livestock?", "What is it like for an illiterate person to learn to use a computer to access government services?"[2].The illustrative research questions refer to a specific setting and are not concerned with explaining how specific contextual factors influence the phenomena rather, the concern is in understanding the essence of the phenomena. The attention of an ICT phenomenologist researcher should be geared towards the meaning of the experience of accessing health services remotely, the experience of using ICT on the life of a farmer, and the experience of overcoming illiteracy to access government services as illustrated by the research questions stated above.

\section{B. Phenomenology in understanding ICT scarcity}

Phenomenology can be applied in ICT research to understand the experiences individuals go through due to the scarcity of ICT infrastructures and skills. The scarcity of ICT infrastructures and skills exists. It is not enough to 
understand the factors influencing the scarcity but rather to further understand the experience such individuals go through due to the scarcity. Some of the research questions that can guide extracting lived experiences on the scarcity of ICT would include but not limited to "What is it like not to be able to chat with a loved one in a foreign country?" "What is it like not to be able to use a computer to send an email?"

C. Phenomenology in finding the root cause of Information Technology related issues ICT organization

In previous research, empirical surveys have been to describe the root cause of problems in ICT organizations. However, knowing the cause of the problem is not sufficient enough to warrant the best way of solving it. There is a need to understand the experience the individual goes through in understanding and trying to solve the problem. For instance, knowing the low efficiency of an IT personal is as a result of a lack of skills or appropriate IT tools is not enough to solve the problem at hand. There is a need to understand the experience the said individual goes through in Using IT tools with insufficient skills and tools. Saraswat [21] researched to investigate issues related to the deployment of ICT in a large multinational enterprise in India. The study revealed that ICT culture in an organization, organizational ICT policies, and organization ICT sociology are the topmost issues in which the phenomenology approach can be applied to, to reveal hidden dimensions and root causes of ICT related problems which may not be clear from an empirical survey.

ICT studies are geared more towards quantitative research because of the philosophical stance underpinning it. This is not to mean that qualitative approaches have not been applied in ICT. Qualitative approaches such as ethnography, and grounded theory and thematic analysis have played a significant role in ICT research. However, these approaches focus on the wholeness of the event under study and seek to provide a theoretical insightful explanation through close interactions with participants. A theoretical explanation is not sufficient enough to understand the experience an individual goes through which is what makes phenomenology distinctive. Phenomenology takes a step further to emphasize intuitions, imagination and universal structures in obtaining a picture of the dynamics that underlay the experience, account for and provide an understanding of perception, feelings and thought evoked regarding a specific experience [2]. The phenomenologist does not focus on the impact or existence of a certain technology rather on the interaction between technology and people.

\section{Applicability of Phenomenology Approach in the Field of ICT}

In the field of ICT, the phenomenology approach has been applied in educational technology research in an attempt to try and understand the experiences teachers' and students' go through during the teaching and learning process. The experiences are divided into three streams of research: (1) Students' experiences with online education (2) Teachers' experiences as they integrate technology in teaching and (3) User's psychological experiences with computer application [19].

The stream of research on students' experiences with online education involves the experiences students' go through when taking courses online, perception of e-learning [22], distant education and assessment. The literature review revealed a small number of applications in understanding student experiences. For example, Cilesiz [23] conducted a phenomenological study of adolescents' experience on the educational use of computers at internet cafes in Turkey. The study aimed to understand and describe the educational use of computers in-depth and arrive at the essence of adolescent experience with the phenomenon.

The stream of research on teachers' experiences as they integrate technology in teaching includes teachers' self-studies using technology, teachers' experiences with Learning Management Systems and pre-service teacher experiences with technology. For example Boorang et al. [24] Conducted a phenomenological study on teachers' views and perceptive on using technology in teaching and learning. Eight full time elementary and secondary teachers from an international school underwent a semi-structured interview and the data analyzed using phenomenological analysis. Cigdemoglu et al [25] conducted a phenomenological study of instructors' experiences on an open-source learning management system. The study was conducted in a Private university in Ankara Turkey. The findings indicated that instructors have different impressions from the system in terms of their efforts and expectation. Yuksel-Arslan et al [26] conducted a phenomenological study on teachers' experiences of using digital storytelling in early childhood education.

The stream of research on user's psychological experiences with computer application which is concerned with experiences of individuals as they interact with internet and multimedia learning applications. For example, Chan et al [27] conducted a study on students' lived experiences of using smartphones in diverse learning contexts using a hermeneutic phenomenological approach. Sandi-Urena [28] conducted a phenomenological study that investigated students' experiences of change in instructional style from a traditional laboratory program to one that was cooperative and project-based. Howard [29] investigated a phenomenological examination of first-time computer experience of adults. Li [30] conducted a mixed-method study on the perception of teachers and students in a Canadian school on the use of technology. Miller et al [31] investigated the experiences individuals have when conversing with digital pedagogical agents. 


\section{Conclusions}

The philosophical stance underpinning ICT research is a positivistic approach in which the world is seen as composed of objects that humans can study, understand and manipulate. It is a view accepted by quantitative researchers [4]. From a sociological perspective, everything in society is seen as objects that can be numbered, counted and quantified, therefore society is seen as something external which shapes human action. On the other hand, phenomenology takes a humanistic approach which is rooted in the understanding that human activity is the force that creates what we perceive to be the society. This contrast makes the application of phenomenology approach in the field of ICT a challenge.

Phenomenology is a powerful research approach that is suitable for exploring challenging problems in the field of ICT. By understanding its nature of studies and working to ensure proper alignment between the specific research question and researchers' underlying philosophy it can be applied in ICT research. Phenomenology can be applied in ICT during data collection, in trying to understand ICT scarcity and technological attitude of people in contemporary society. However, in circumstances such as analyzing qualitative data [4], it is unsuitable due to the nature of qualitative data. Since there is no single agreed-upon method for conducting phenomenological research because each approach draws on a different philosophical perspective, therefore one must be able to articulate the specific philosophical underpinnings associated with each approach and the suitability of each approach. An important finding from the different studies that have applied phenomenology is that empiricism and phenomenology do not oppose each other, rather while empiricism helps understand what happens in ICT use, phenomenology helps to uncover the root cause behind the empirical observation. Therefore it is important to know areas in ICT research where phenomenology is most suitable.

\section{REFERENCES}

[1] B. E. Neubauer, C. T. Witkop, and L. Varpio, "How phenomenology can help us learn from the experiences of others," Perspect. Med. Educ., vol. 8, no. 2, pp. 90-97, 2019.

[2] A. D. Andrade, A. A. Techatassanasoontorn, and H. Singh, "Phenomenology: Understanding the ICT4D experience," AMCIS 2017 - Am. Conf. Inf. Syst. A Tradit. Innov., vol. 2017-Augus, pp. 1-10, 2017.

[3] A. Teherani, T. Martimianakis, T. Stenfors-Hayes, A Wadhwa, and L. Varpio, "Choosing a Qualitative Research Approach,” J. Grad. Med. Educ., vol. 7, no. 4, pp. 669-670, 2015.

[4] K. A. Roberts and R. W. Wilson, "ICT and the research process: Issues around the compatibility of technology with qualitative data analysis," Forum Qual. Soc. Res., vol. 3, no. 2, 2002.

[5] M. van Manen, "Researching Lived Experience: Human Science for an Action Sensitive Pedagogy," 2016.

[6] P. K. Astalin, "Qualitative Research Design : A conceptual Framework," Int. J. Soc. Sci. Interdisciplinary Res., vol. 2, no. 1, pp. 118-124, 2013.

[7] C. Goulding, "Grounded theory, ethnography and phenomenology strategies for marketing research," emerald J. Mark., vol. 39, pp. 294-306, 2005.

[8] K. D. Valentine, T. J. Kopcha, and M. D. Vagle, "Phenomenological Methodologies in the Field of Educational Communications and Technology," TechTrends, 2018.

[9] H. Carel, "Phenomenology and its application in medicine," Theoretical Med., no. November 2010, pp. 33-46, 2011.

[10] L. Kuller, "Is Phenomenology the Best Approach to Health Research ?," Am. J. Epidemiol., vol. 166, no. 10, pp. 1109 $1115,2007$.

[11] A. Gurwitsch, "The Phenomenological and the Psychological Approach to Consciousness," Int. Phenomenol. Res., vol. 15, no. 3, pp. 303-319, 2016.

[12] A. S. Davidsen, "Phenomenological Approaches in Psychology and Health Sciences," Qual. Res. Psychol., pp. 318-339, 2013.

[13] R. Desjarlais and C. J. Throop, "Phenomenological Approaches in Anthropology," Annu. Rev. Anthropol., no. August, pp. 87-102, 2011.

[14] A. J. H. Leech, "Another Look at Phenomenology and Religious Education," Br. J. Relig. Educ., vol. 11, no. 2, pp. 70-75, 1989.

[15] J. Awang and Y. M. Ramli, "Theological and phenomenological methods in teaching comparative religion courses," Procedia - Soc. Behav. Sci., vol. 18, pp. 180-186, 2011.

[16] F. L. Lacdo-o, G. N. District, M. V. P. Macawile, and M. A. Caliwan, "The ' Need to Transcend ': A Phenomenological Study on the Lived Experiences of Millennial Teachers," Int. J. Sci. Res. Educ., vol. 11, no. September, pp. 318-334, 2018 .

[17] J. Lymbery, "Listening to student voices: A phenomenological investigation of the student experience of using technology for learning .," 2017.

[18] A. D. Thompson, "Scientifically Based Research : Establishing a Research Agenda For The Technology in Teacher Education Community," J. Res. Technol. Education, vol. 37 , no. 4, pp. 331-337, 2005.

[19] S. Cilesiz, "A phenomenological approach to experiences with technology: current state, promise, and future directions for research," Educ. Technol. Res. Dev., pp. 487 510,2011

[20] K. Riemer and R. B. Johnston, "Rethinking the place of the artefact in IS using Heidegger's analysis of equipment," Eur. J. Inf. Syst., vol. 23, no. 3, pp. 273-288, 2014. 
[21] S. P. Saraswat, "Journal of Global Information A Phenomenological Investigation of Information and Communications Technology at a Multinational Enterprise from India," no. November, pp. 37-41, 2014.

[22] F. Concannon, A. Flynn, and M. Campbell, "What campus-based students think about quality and benefits of e-learning," Br. J. Educ. Technol., vol. 36, no. 3, pp. 501$512,2005$.

[23] S. Cilesiz, "Educational Computer Use in Leisure Contexts: A Phenomenological Study of Adolescents' Experiences at Internet Cafés," Am. Educ. Res. J., vol. 46, no. 1, pp. 232274, 2009.

[24] M. A. Boorang, “A Phenomenological Study on Teacher' s View and Perspectives on Using Technology in Teaching \& Learning," J. Soc. Sci. Res., pp. 748-755, 2018.

[25] C. Cigdemoglu, H. Ozge, and H. Akay, "Social and A phenomenological study of instructors " experiences on an open-source learning management system," Soc. Behav. Sci., vol. 28, pp. 790-795, 2011.

[26] P. Yuksel-Arslan, S. Yildirim, and B. R. Robin, "A phenomenological study: teachers ' experiences of using digital storytelling in early childhood education," Educ.
Stud., vol. 5698, no. June 2016.

[27] N. Nee, C. Walker, and A. Gleaves, "An exploration of students ' lived experiences of using smartphones in diverse learning contexts using a hermeneutic phenomenological approach," Comput. Educ., vol. 82, pp. 96-106, 2015.

[28] P. S. Issue, "Phenomenological Approaches to study Learning in the Tertiary Level Chemistry Laboratory," Quim Nov., vol. 41, no. 2, pp. 236-242, 2018.

[29] D. C. P. Howard, "Human-computer interactions: a phenomenological examination of the adult first-time computer experience," Int. J. Qual. Stud. Educ., no. February 2015, pp. 37-41, 2006.

[30] Q. Li, "Student and Teacher Views About Technology: A Tale of Two Cities ?," J. Res. Technol. Educ., vol. 39, no. 4, pp. 377-397, 2007.

[31] C. Miller, G. Veletsianos, and A. Doering, "Curriculum at forty below: a phenomenological inquiry of an educator/explorer's experience with adventure learning in the Arctic," Distance Educ., pp. 37-41, 2008. 